\title{
Systemic T Cell Subsets and Cytokines in Patients With Homozygous Sickle Cell Disease and Asymptomatic Urinary Tract Infections in Togo
}

\author{
Christèle Nguepou Tchopba, PhD, ${ }^{1}$ Gnatoulma Katawa, PhD, ${ }^{1}$ Essohana Padaro, MD, ${ }^{2}$ Pélagie Edlom Tchadié, MSc, ${ }^{1}$ \\ Simplice Damintoti Karou, PhD, ${ }^{1}$ Ahoefa Vovor, MD, ${ }^{2}$ Yaovi Ameyapoh, PhD ${ }^{1}$ \\ ${ }^{1}$ Unité de Recherche en Immunologie et Immuno-modulation (UR2IM)/Laboratoire de Microbiologie et de Contrôle Qualité des Denrées \\ Alimentaires (LAMICODA)/Ecole Supérieure des Techniques Biologiques et Alimentaires (ESTBA)-Université de Lomé, Togo, West Africa \\ ${ }^{2}$ Département des Sciences Fondamentales, Faculté des Sciences de la Santé (FSS)-Université de Lomé, Togo, West Africa
}

Background: In sickle cell disease (SCD), cytokine expression influences the pivotal pathways that contribute to disease pathogenesis. Additional infection could affect the immune profile of patients with SCD and increase disease mortality. The aim of this study was to investigate the cytokines and T helper cells profile in patients with asymptomatic urinary tract infection and homozygous SCD (HbSS).

Methods: From July to September 2018, 22 HbSS subjects were recruited at Centre Hospitalier Universitaire Campus in Lomé, Togo, 12 of whom had urinary tract bacterial infections and 10 of whom were uninfected. Cytokines from plasma were measured by the enzyme-linked immunosorbent assay (ELISA) sandwich method, and immune cell profiles were performed by flow cytometry. The immunogenicity of bacteria-derived antigens isolated from the urine of $\mathrm{HbSS}$ subjects with asymptomatic urinary tract infections was studied in a cell culture system, and the induction of the cytokines was measured.

Results: The mean age of HbSS subjects with urinary tract infections was $20.33 \pm 3.58$ years, and the male/female ratio was 0.09 (1:11). HbSS subjects with asymptomatic urinary tract infections had elevated plasma levels of interferon gamma (IFN- $\gamma$ ) and interleukin (IL)-10. CD4 ${ }^{+}$Tbet $^{+}$IFN- $\gamma^{+}$and $\mathrm{CD} 4^{+} \mathrm{FoxP}^{+} \mathrm{IL}-10^{+} \mathrm{T}$ cell populations were decreased in HbSS subjects with asymptomatic urinary tract infections. Bacterial antigens from $\mathrm{HbSS}$ subjects induced the production of IL-10 but not IFN- $\gamma$ in uninfected volunteer donors (HbAA).

Conclusion: Our study demonstrated that patients with SCD and asymptomatic urinary tract infections had elevated IFN- $\gamma$ and IL-10 levels. This chronic inflammatory condition could be a risk for this group of patients in terms of vaso-occlusive crisis. Systematic cytobacteriologic examination of the urine of HbSS subjects would be of interest.

Keywords: Asymptomatic urinary tract infections, cytokines, immune response, sickle cell disease, Thelper cells, Togo

Address correspondence to Christéle Nguepou Tchopba, PhD, UR2IM/LAMICODA-ESTBA-Université de Lomé, Bvd Eyadéma, 01 BP 1515 , Lomé, Togo. Tel: +228 980665 33. Email: chrisnono@live.com

\section{INTRODUCTION}

Sickle cell disease (SCD) is a neglected genetic disease, especially in Africa, where an estimated $50 \%$ to $90 \%$ of patients die undiagnosed before their fifth birthdays. ${ }^{1}$ Globally, approximately 300,000 infants per year are born with homozygous SCD (HbSS). ${ }^{2}$ In Togo, a country of the West African region with approximately 7.889 million people, SCD is the most common hemoglobin $(\mathrm{Hb})$ abnormality. ${ }^{3}$ The frequency of the $\mathrm{HbS}$ gene has been estimated at $16.1 \%$, the prevalence of $\mathrm{HbSS}$ at $1.3 \%$, and the prevalence of the double heterozygous forms $(\mathrm{HbSC}$ and $\mathrm{HbS} / \beta$-thalassemia [ $\beta$ thal]) at $2.6 \%$. Approximately 200,000 Togolese are estimated to have a major form of SCD (HbSS, HbSC, or $\mathrm{HbS} / \beta$ thal). ${ }^{3}$
Patients with SCD have an increased inflammatory profile compared to healthy individuals $(\mathrm{HbAA})$. The chronic inflammatory state in SCD is associated with factors such as endothelial damage; increased production of reactive oxygen species; hemolysis; increased expression of adhesion molecules by leukocytes, erythrocytes, and platelets; and increased production of proinflammatory cytokines. ${ }^{4}$ In SCD, cytokine expression influences the pivotal pathways that contribute to disease pathogenesis. ${ }^{5}$ Some authors have noted that the level of inflammatory cytokines is higher during a vaso-occlusive crisis than in steady state. .-8 $^{6-8}$

Infections significantly contribute to morbidity and mortality in patients with SCD. ${ }^{9,10}$ Bacterial infection, one of the principal complications of SCD, can occur as an acute or 
chronic condition. ${ }^{9,11}$ Patients with SCD have an increased risk of urinary tract infection (UTI), and kidney diseases are usually more severe in HbSS patients compared to HbAA individuals $^{12}$; kidney diseases account for $16 \%$ to $18 \%$ of mortality in patients with SCD. ${ }^{13}$

Asymptomatic UTI is defined as the isolation of a specific number of bacteria (more than $10^{3}$ to $10^{5}$ bacteria/mL depending on the species) from a urine sample that was collected in an appropriate manner, but the patient does not have symptoms or signs related to a UTI. ${ }^{14}$ Such a situation can be a prelude to a high risk of pyelonephritis, kidney failure, or even sepsis. ${ }^{15}$

Immune response during a UTI is highly activated. Innate immunity acts through the mechanical action of eliminating urine and also activates inflammation to eliminate bacteria. Adaptative immunity is involved for bacterial elimination through $\mathrm{T}$ helper or $\mathrm{CD}^{+}{ }^{+} \mathrm{T}$ lymphocytes. ${ }^{16}$ Inflammatory, anti-inflammatory, and regulatory cytokines, which are mediators of the immune response, are also involved. ${ }^{17}$

In 2019 , we found that approximately $9.3 \%$ of Togolese patients with homozygous SCD had an asymptomatic UTI. ${ }^{18}$ Because SCD is an inflammatory disease and knowing that UTIs activate inflammation, we hypothesized that UTIs may exacerbate the inflammatory immune response in patients with SCD.

For this study, we investigated the systemic cytokines and Thelper cells profiles in Togolese patients with homozygous SCD and asymptomatic UTIs.

\section{METHODS}

\section{Study Population and Sample Collection}

Subjects enrolled for this study have been previously described. ${ }^{18}$ The study population was recruited at Centre Hospitalier Universitaire Campus (CHU Campus) in Lomé, Togo, which had a clinical hematology unit for the follow-up of patients with SCD living in Togo.

From July to September 2018, 129 patients with SCD were consecutively recruited for cytobacteriologic examination of urine. Included in this study were patients with the HbSS genotype who were followed at the CHU Campus; were in steady state according to medical opinion; did not take antibiotics during the prior 2 weeks ${ }^{19}$; were not taking any medications; and did not have kidney disease, diabetes, or any other disease. We found that 12 patients had UTI bacteria at a significant level. From the recruited patients with SCD, we selected $10 \mathrm{HbSS}$ subjects free of UTI bacteria. For comparison, we recruited heterozygous bloodrelated HbAS subjects $(n=10)$ and healthy volunteers $(\mathrm{HbAA})$ $(n=11)$ who were members of the $\mathrm{CHU}$ Campus laboratory staff. $\mathrm{HbAS}$ and $\mathrm{HbAA}$ subjects were free of UTI bacteria. Blood samples were collected at the CHU Campus in Lomé, Togo, and immunological assays were performed at Unité de Recherche en Immunologie et Immunomodulation of Laboratoire de Microbiologie et de Contrôle des Denrées Alimentaires of Ecole Supérieure des Techniques Biologiques et Alimentaires-Université de Lomé.

\section{Cytobacteriologic Examination of Urine}

Cytobacteriologic examination of urine was performed for all subjects. A sterile vial and instructions were given for the collection and transport of urine samples. Participants collected their urine samples at home early in the morning (approximately 6:00 am) at least 4 hours after the last urination and in strict hygienic conditions. The samples were received from 7:00 am to 9:30 am at the bacteriology laboratory on the $\mathrm{CHU}$ Campus. Samples were stored at $4^{\circ} \mathrm{C}$ from time of receipt until the start of handling. All urine samples were cultured, using a sterile calibrated loop, on UriSelect 4 chromogenic medium (Bio-Rad Laboratories, Inc) for 18 to 24 hours at $37^{\circ} \mathrm{C}$. The remaining volume of urine was then centrifuged at $4,000 \mathrm{rpm}$ for 5 minutes. The pellets were examined for leukocytes, red blood cells, urinary crystals, granular cylinders, and parasites. Leukocyturia was determined on a Nageotte cell and was considered significant if $10^{4} \mathrm{cells} / \mathrm{mL}$. Bacterial identification was performed, and bacteriuria was determined by counting bacterial colonies on an agar plate and multiplying the result by the loop volume $(\times 10){ }^{18}$

\section{T Helper Cell Profiling}

To assess the $T$ helper cell profile of the study population, $100 \mu \mathrm{L}$ of whole blood cells was activated in duplicate with $50 \mu \mathrm{L}$ of $1 \times$ concentrated cell stimulation cocktail plus protein transport inhibitors containing $40 \mu \mathrm{M}$ of phorbol 12-myristate 13-acetate (PMA), $670 \mu \mathrm{M}$ of ionomycin (as antibiotic), $5.3 \mathrm{mM}$ of Brefeldin $\mathrm{A}$ (as protein transport inhibitor), and $1 \mathrm{mM}$ of Monensin, all in $500 \times$ concentrated ethanol (Invitrogen/Thermo Fisher Scientific) for 6 hours at $37{ }^{\circ} \mathrm{C}$ under $5 \%$ carbon dioxide $\left(\mathrm{CO}_{2}\right)$. Samples were collected, and red blood cells were lysed with $200 \mu \mathrm{L}$ of red blood cell lysis buffer (Roche Diagnostics) according to manufacturer instructions. Cells were then stained for $\mathrm{T}$ helper type 1 (Th1), T helper type 2 (Th2), and natural regulatory $\mathrm{T}$ (nTreg) cells surface markers; intracellular cytokines; and transcription factors. Surface staining was performed using antihuman CD4-APC antibody (clone A16A1) and incubated at $4{ }^{\circ} \mathrm{C}$ for 30 minutes. Then, cells were washed and permeabilized using Fix \& Perm reagent (Invitrogen/Thermo Fisher Scientific). After blocking Fc receptors with TruStain FcX (BioLegend), cells were stained in 3 different panels: (1) Th1 as antihuman interferon gamma (IFN- $\gamma$ )-FITC (clone 4S.B3) and Tbet-PE (clone 4B10); (2) Th2 as antihuman interleukin (IL)-4-FITC (clone MP4-25D2) and GATA3-PE (clone 16E10A23); and (3) nTreg as antihuman IL-10-PE (clone JES3-9D7) and antihuman FoxP3-FITC (clone 206D). After 15 minutes at $4{ }^{\circ} \mathrm{C}$, cells were acquired on CytoFLEX flow cytometer (Beckman Coulter), and data were analyzed with CytExpert 2.1 software (Beckman Coulter). Fluorescence compensation was done using VersaComp Antibody Capture Bead Kit (Beckman Coulter) to correct spectral overlap. The gating strategy is depicted in Figure 1.

\section{Bacterial Antigen Preparation}

We investigated the immunogenicity of 3 clinical strains of Escherichia coli (randomly named S1, S2, and S3) isolated from the urine of HbSS subjects. These bacterial strains were obtained after 24-hour urine culture on UriSelect 4 agar and identified. Thereafter, bacterial strains were stored on microbeads (Microorganism Preservation System - Protect, Technical Service Consultants Ltd) at $-20^{\circ} \mathrm{C}$ for 3 months. Bacteria were then cultured on the UriSelect 4 medium for 24 hours at $37^{\circ} \mathrm{C}$. One colony was selected and cultured in Oxoid Mueller-Hinton Broth (ThermoFisher Scientific). Bacteria were inactivated at $56 \pm 1{ }^{\circ} \mathrm{C}$ for 6 hours in a water 


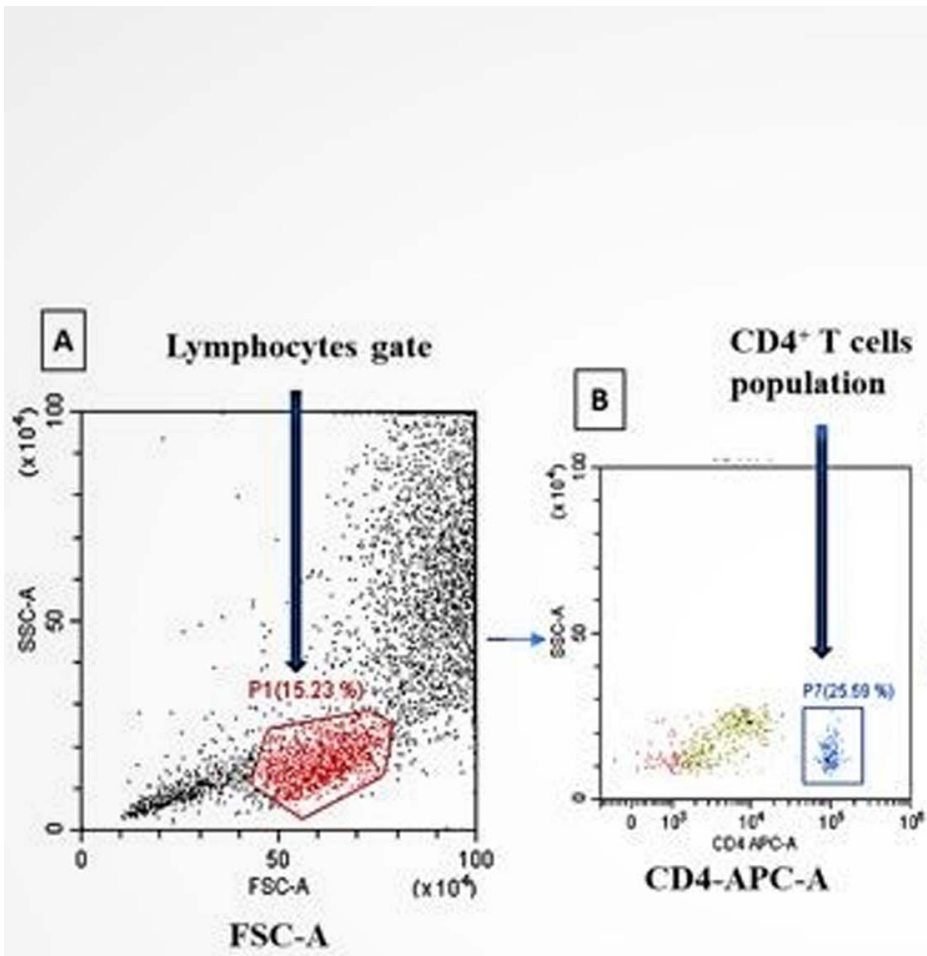

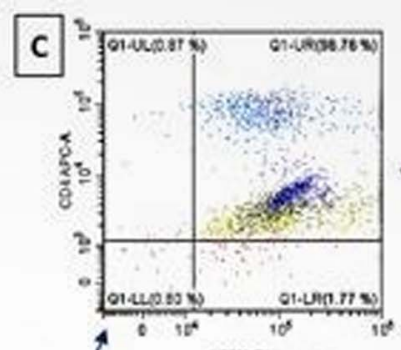
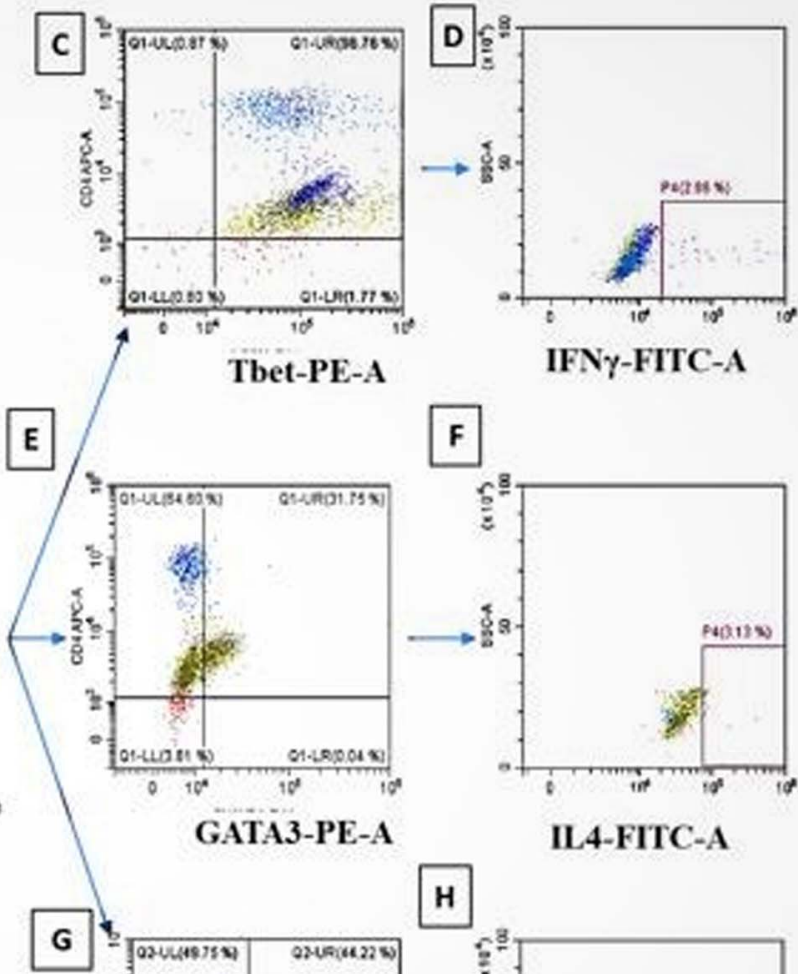

IFN $\gamma$-FITC-A

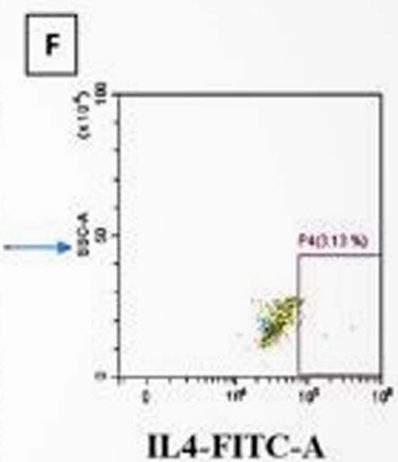

GATA3-PE-A

H

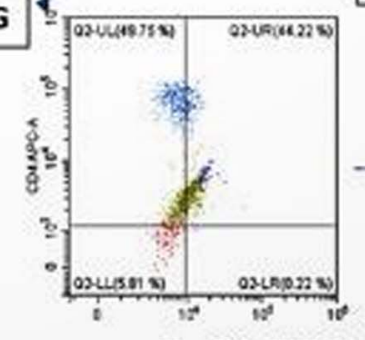

FoxP3-FITC-A

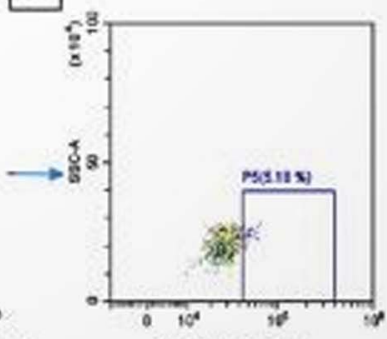

IL10-PE-A

Figure 1. Gating strategy: (A) Lymphocyte gate; (B) CD4 ${ }^{+}$T lymphocyte population (LTCD4 ${ }^{+}$) delineated among the lympho-

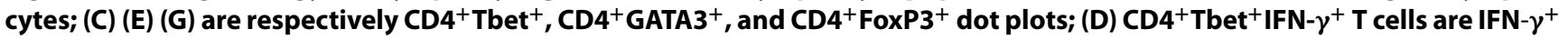
cells delineated among $\mathrm{CD}^{+}{ }^{+}$bet $^{+}$cells; (F) CD4 ${ }^{+} \mathrm{GATA}^{+}{ }^{+} \mathrm{IL}-4^{+}$T cells are IL-4 ${ }^{+}$cells delineated among $\mathrm{CD4}^{+} \mathrm{GATA3}^{+}$cells; and (H) $\mathrm{CD4}^{+}{ }^{+} \mathrm{FoxP3}^{+} \mathrm{IL}_{-10^{+}} \mathrm{T}$ cells are IL- $10^{+}$cells delineated among $\mathrm{CD4}^{+}{ }^{+}$FoxP3 ${ }^{+}$cells.

bath, ${ }^{20}$ followed by triple washing with Dulbecco's phosphate buffered saline (DPBS) (ThermoFisher Scientific). To assess the complete inactivation, a bacterial culture on brain heart infusion agar (Liofilchem, Inc) was performed.

After complete inactivation of bacteria, tubes containing the culture broth were centrifuged, and the pellet was collected and added to $1 \mathrm{~mL}$ of DPBS. The protein concentration was measured by Bradford assay. Bacterial antigens obtained were frozen at $-20^{\circ} \mathrm{C}$ for further use.

\section{Isolation of Peripheral Blood Mononuclear Cells}

Blood samples $(20 \mathrm{~mL})$ in K3 EDTA tubes from 6 healthy volunteer donors from the national blood bank of Lomé were collected, and peripheral blood mononuclear cells (PBMCs) were isolated by the Ficoll density gradient centrifugation method described by Katawa et al. ${ }^{21}$ In brief, $20 \mathrm{~mL}$ of whole blood was diluted in $15 \mathrm{~mL}$ of DPBS and carefully added to $15 \mathrm{~mL}$ of Pancoll separating solution (PAN-Biotech). After 20 minutes' centrifugation at 2,000 rpm, the white layer of PBMCs was collected and washed 3 times in Roswell
Park Memorial Institute (RPMI) medium supplemented with gentamicin $50 \mu \mathrm{g} / \mathrm{mL}$, penicillin-streptomycin $100 \mu \mathrm{g} / \mathrm{mL}$, L-glutamine $2 \mathrm{mM} / \mathrm{mL}$, and fetal bovine serum (FBS) at $10 \%$ (PAN-Biotech). Cells were counted, and their viability was assessed using the trypan blue exclusion method.

\section{In Vitro Cell Culture}

For the cell culture performed in a 96-well U-bottom plate (Greiner Bio-One), $2 \times 10^{5}$ PBMCs per well were incubated, in duplicate, without or with $1 \mu \mathrm{g} / \mathrm{mL}$ of bacteria extracts and with $1 \mathrm{ng} / \mathrm{mL}$ of lipopolysaccharide (InvivoGen) as positive control ${ }^{22}$ in RPMI medium supplemented with FBS at $10 \%$. Cells were then incubated at $37^{\circ} \mathrm{C}$ under $5 \% \mathrm{CO}_{2}$ for 24 hours and 72 hours.

\section{Cytokines Measurement}

Blood samples were spun at 4,000 rpm for 5 minutes, and plasma was collected. Plasma samples of subjects and culture supernatants were stored at $-20{ }^{\circ} \mathrm{C}$ until experimental analysis. Samples were thawed once for type 1 (IL-6 and 


\begin{tabular}{lccccc}
\hline & \multicolumn{3}{c}{ Population } \\
\cline { 2 - 6 } Variable & $\begin{array}{c}\text { HbSS With Infection }^{\mathbf{a}} \\
\mathbf{n = 1 2}\end{array}$ & $\begin{array}{c}\text { HbSS }^{\mathbf{b}} \\
\mathbf{n = 1 0}\end{array}$ & $\begin{array}{c}\text { HbAS }^{\mathbf{c}} \\
\mathbf{n = 1 0}\end{array}$ & $\begin{array}{c}\text { HbAA }^{\mathbf{d}} \\
\mathbf{n = 1 1}\end{array}$ & $\boldsymbol{P}_{\text {Value }}$ \\
\hline Age, years, mean \pm SD & $20.33 \pm 3.58$ & $21.10 \pm 2.31$ & $26.00 \pm 2.89$ & $27.27 \pm 1.70$ & 0.106 \\
Age ratio: $<18$ years: $\geq 18$ years & $6: 6$ & $5: 5$ & $1: 9$ & $0: 11$ & 0.011 \\
Sex ratio: male:female & $1: 11$ & $4: 6$ & $5: 5$ & $8: 3$ & 0.018 \\
\hline
\end{tabular}

${ }^{a} \mathrm{HbSS}$ with infection, subjects with homozygous sickle cell disease and with urinary tract infection.

${ }^{b} \mathrm{HbSS}$, subjects with homozygous sickle cell disease and without urinary tract infection.

${ }^{\mathrm{c}} \mathrm{HbAS}$, heterozygous subjects without urinary tract infection.

${ }^{\mathrm{d}} \mathrm{HbAA}$, subjects without sickle cell disease or sickle cell trait and without urinary tract infection.

tumor necrosis factor [TNF]- $\alpha$ ) and type 2 (IFN- $\gamma$, IL-5, and IL-10) cytokine measurement by the sandwich enzymelinked immunosorbent assay (ELISA) method using an Invitrogen kit (ThermoFisher Scientific). Cytokine concentrations were measured using a HumaReader HS (HUMAN Diagnostics Worldwide).

\section{Statistical Analysis}

Sample size was calculated according to a 2010 study from Nigeria, in which the researchers found that $4 \%$ of patients with SCD have asymptomatic bacteriuria. ${ }^{23}$ Using the formula $n=\left[Z 1 / 2^{2 *} p(1-p)\right] / d^{2}$, where $n$ is the sample size, $p$ is the prevalence of the disease in the population, $Z 1 / 2^{2}$ is equal to 1.96 , and $d$ is the tolerable sampling error $(0.05),{ }^{23}$ we found that the minimal sample size required for our study was 59.

Statistical analyses were performed using Prism, version 5.02 (GraphPad Software Inc). To compare cytokines and cell profiles, a Mann-Whitney $U$ test was used to compare 2 groups. The mean ages of the 4 study groups were compared using a Kruskal-Wallis test. Chi-square test was used to compare the ratio of ages $(<18 / \geq 18$ years) and the ratio of sexes. $P$ values $<0.05$ were considered significant.

\section{Ethics Approval and Consent to Participate}

This study was approved by the Bioethics Committee for Health Research from the Togo Ministry of Health (No. 15/2018/CBRS). Written informed consent was obtained from all subjects. For minors, a parent's consent was obtained.

\section{RESULTS \\ Characteristics of the Studied Populations}

Demographic characteristics of the studied populations are shown in the Table. We found no significant difference in the mean ages of the 4 groups, but we found significant differences in the age ratio $(<18 / \geq 18$ years $)$ and the sex ratio among the 4 groups $(P=0.011, P=0.018$, respectively).

The mean age of HbSS subjects who had a UTI was 20.33 \pm 3.58 years, and the ratio of males to females was $1: 11$. The uninfected subjects (HbSS, HbAS, or $\mathrm{HbAA}$ ) had leukocyturia $<10^{4}$ cells $/ \mathrm{mL}$ and no significant bacteriuria $\left(<10^{5}\right.$ bacteria/mL), whereas the infected subjects had leukocyturia $\geq 10^{4}$ cells $/ \mathrm{mL}$ and bacteriuria: $\geq 10^{3}$ bacteria $/ \mathrm{mL}$ for E. coli (for males and females); $\geq 10^{3}$ bacteria/mL for Staphylococcus spp (for males); $\geq 10^{4}$ bacteria/mL for Staphylococ- cus spp (for females); $\geq 10^{5}$ bacteria/mL for Enterococcus spp, Streptococcus spp, and Enterobacter spp (for males and females). In cases of leukocyturia $<10^{4}$ cells $/ \mathrm{mL}$, bacteriuria $\geq 10^{5}$ bacteria/mL was considered UTI positive for all bacteria.

The most common strains of bacteria responsible for the UTIs were E coli (66.67\%), Enterobacter spp (8.33\%), Staphylococcus spp (8.33\%), Enterococcus spp (8.33\%), and Streptococcus spp (8.33\%).

\section{Elevated Plasma Levels of IFN- $\gamma$ and IL-10 in Infected HbSS Subjects}

HbSS subjects presenting with UTI had elevated plasma levels of IFN- $\gamma$ and IL-10 compared to uninfected HbSS, $\mathrm{HbAS}$, and $\mathrm{HbAA}$ subjects (Figure 2). Levels of IFN- $\gamma$ were high in uninfected HbSS subjects compared to HbAS subjects. No differences were found between subjects with $\mathrm{HbAS}$ and $\mathrm{HbAA}$. IL-10 was also high in uninfected $\mathrm{HbSS}$ subjects compared to HbAS and HbAA subjects. IL-5, IL-6, and TNF- $\alpha$ were not detected in the plasma of all groups.

We compared the cytokine profile in females only (Figure 3). HbSS females with UTI secreted more IFN- $\gamma$ than uninfected $\mathrm{HbSS}$ and $\mathrm{HbAS}$ females, and the difference was significant. A significant difference was also seen in IL-10 levels; $\mathrm{HbSS}$ females, both infected and uninfected, secreted more IL-10 in their plasma than uninfected HbAS females.

\section{Profile of CD4 ${ }^{+} \mathrm{T}$ Cells}

To investigate the source of cytokines of the study population, $\mathrm{CD}^{+} \mathrm{T}$ cells were characterized (Figure 4). $\mathrm{CD}^{+}{ }^{+} \mathrm{Tbet}^{+} \mathrm{IFN}-\gamma^{+}$and $\mathrm{CD} 4^{+} \mathrm{FoxP}^{+} \mathrm{IL}-10^{+} \mathrm{T}$ cell populations were decreased in $\mathrm{HbSS}$ subjects with asymptomatic UTI. However, the percentage of CD4 ${ }^{+}$Tbet $^{+} \mathrm{IFN}-\gamma^{+} \mathrm{T}$ cells was significantly higher in uninfected HbSS subjects compared to uninfected $\mathrm{HbAA}$ subjects. Further, the percentage of $\mathrm{CD}^{+}{ }^{+} \mathrm{Tbet}^{+} \mathrm{IFN}-\gamma^{+} \mathrm{T}$ cells was significantly lower in uninfected $\mathrm{HbAS}$ subjects vs uninfected $\mathrm{HbAA}$ subjects.

The percentage of $\mathrm{CD}^{+}{ }^{+} \mathrm{GATA} 3^{+} \mathrm{IL}-4^{+} \mathrm{T}$ cells in infected $\mathrm{HbSS}$ subjects was significantly higher than the percentage in uninfected HbSS subjects.

The percentages of CD4 ${ }^{+}$FoxP $3^{+} \mathrm{IL}-10^{+} \mathrm{T}$ cells in infected and uninfected $\mathrm{HbSS}$ subjects were significantly lower than the percentage in uninfected $\mathrm{HbAA}$ subjects.

These results indicate that the primary source of IFN- $\gamma$ and $\mathrm{IL}-10$ in the plasma of infected HbSS subjects was not from Th1 or nTreg cells. 

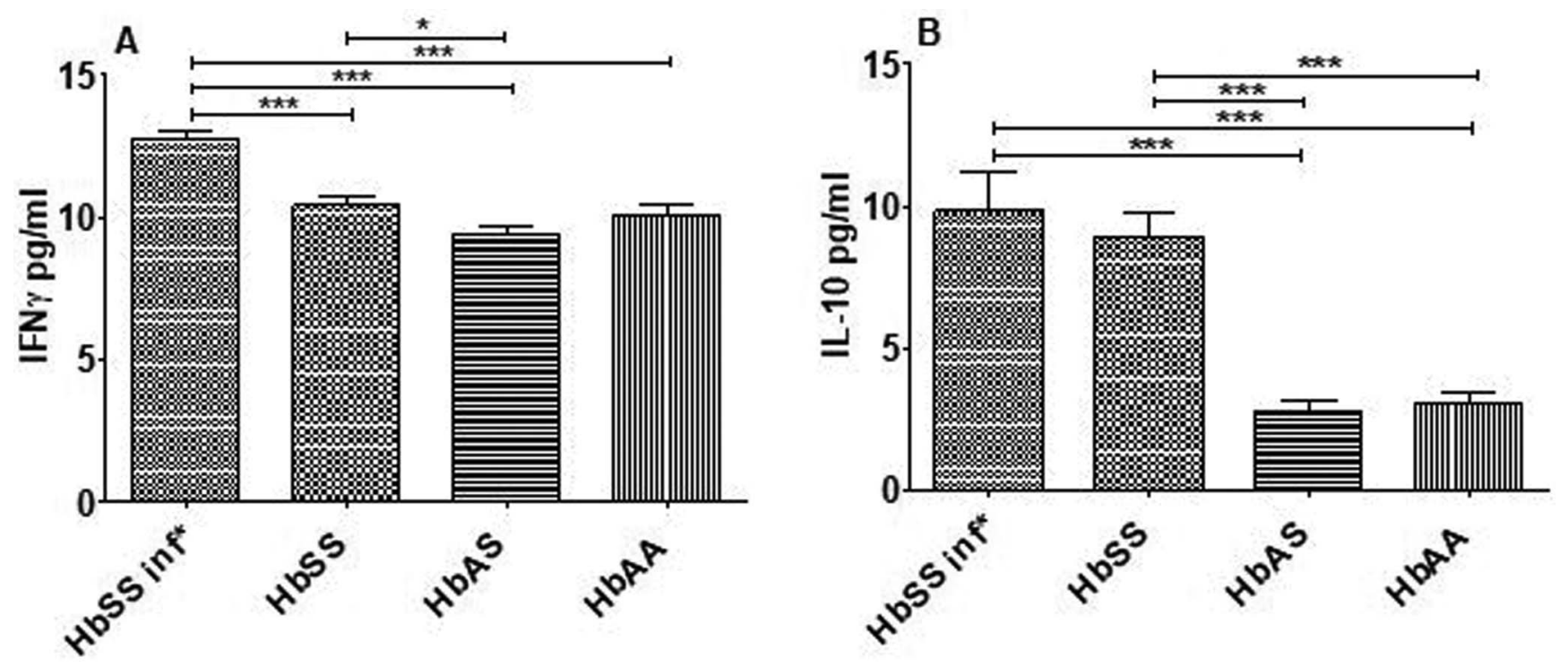

Figure 2. Plasma cytokine profile measured by sandwich enzyme-linked immunosorbent assay method. The graphs show plasma levels of (A) interferon gamma (IFN- $\gamma$ ) and (B) interleukin-10 (IL-10) in HbSS subjects who had urinary tract infections (HbSS inf*, $n=12)$, HbSS subjects who did not have urinary tract infections (HbSS, $n=10)$, uninfected HbAS subjects ( $=10)$, and uninfected HbAA volunteers $(n=11)$. Bars indicate the concentration of cytokines in each group. Data are expressed as mean \pm SEM. Asterisks show statistical differences (Mann-Whitney $U$ test) between the groups $\left({ }^{*} P<0.05\right)$.

\section{Antigens From Strains Isolated From HbSS} Subjects With Asymptomatic Bacteriuria Induced TNF- $\alpha$, IL-6, and IL-10

We examined the capacity of antigens from clinical bacterial strains isolated from the urine of $\mathrm{HbSS}$ subjects to induce inflammatory responses. PBMCs from $\mathrm{HbAA}$ healthy donors were stimulated with antigens from 3 strains of $E$ coli derived from asymptomatic infected HbSS subjects. All 3 bacterial strains induced significant production of proinflammatory cytokines TNF- $\alpha$ and IL- 6 after 24 hours of culture compared to the unstimulated cells (Figure 5).

However, bacterial strains isolated from asymptomatic infected $\mathrm{HbSS}$ subjects did not induce significant production of IFN- $\gamma$ after 72 hours of culture (Figure 6A). Only E coli S1 induced more IL-5 production compared to the unstimulated cells (Figure 6B). In contrast to the IFN- $\gamma$ results, all $E$ coli
IFN $\gamma$ women

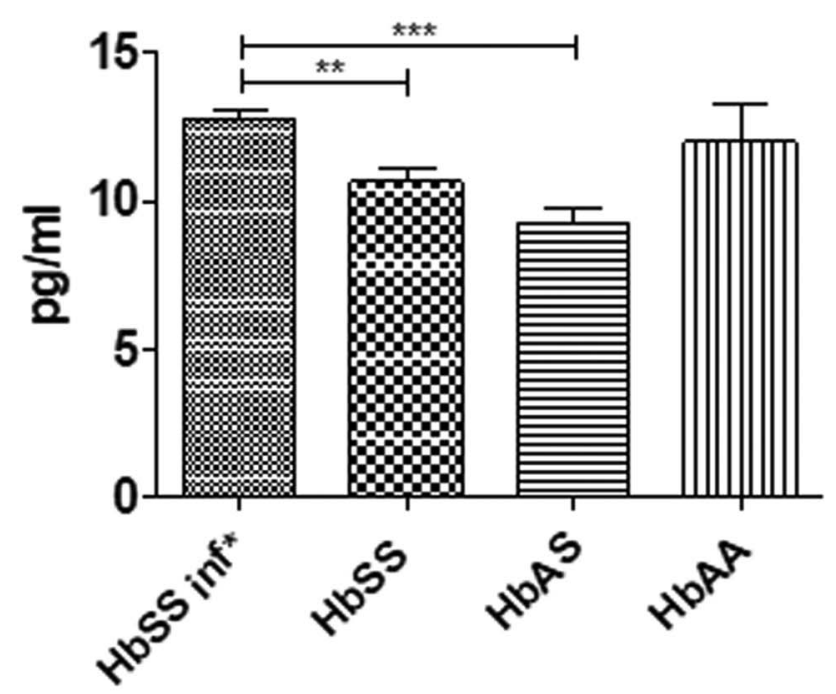

\section{IL-10 women}

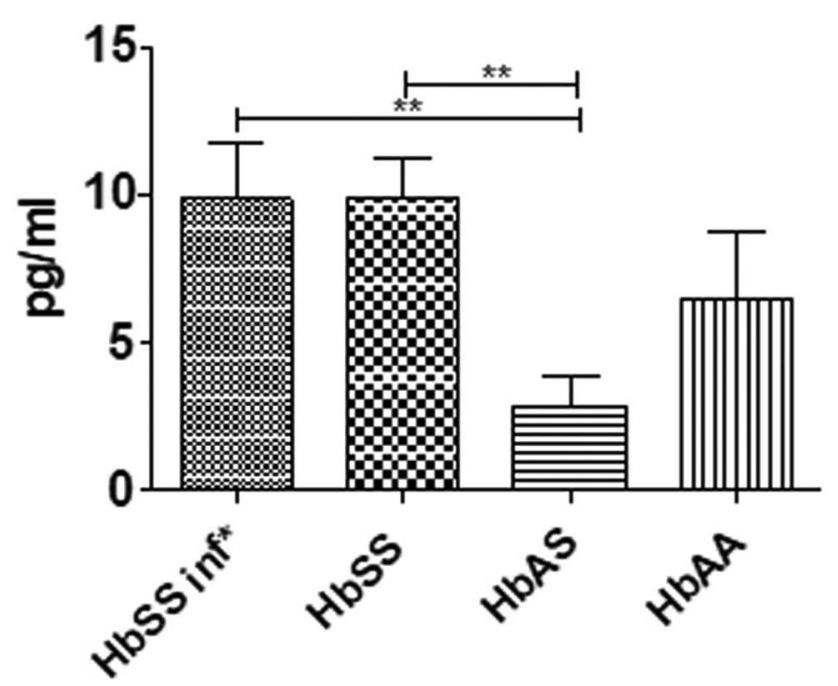

Figure 3. Plasma cytokine profile in females only measured by sandwich enzyme-linked immunosorbent assay method. The graphs show plasma levels of (left) interferon gamma (IFN- $\gamma$ ) and (right) interleukin-10 (IL-10) in HbSS subjects who had urinary tract infections (HbSS inf*, $n=11$ ), HbSS subjects who did not have urinary tract infections $(\mathrm{HbSS}, \mathrm{n}=6)$, uninfected HbAS subjects $(n=5)$, and uninfected HbAA volunteers $(n=3)$. Bars indicate the concentration of cytokines in each group. Data are expressed as mean \pm SEM. Asterisks show statistical differences (Mann-Whitney $U$ test) between the groups $(* P<0.05$ ). 

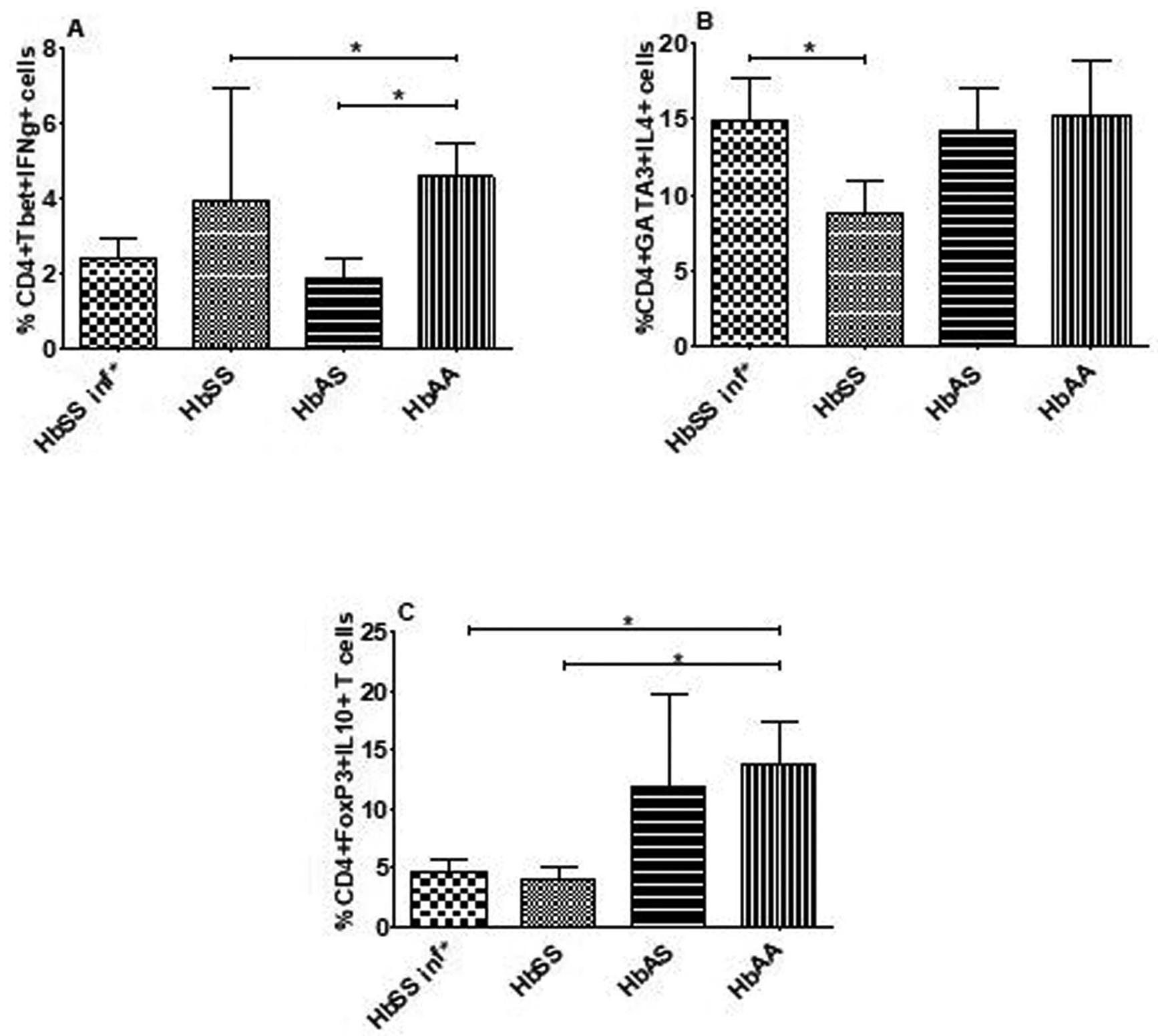

Figure 4. T helper type 1, T helper type 1, and natural regulatory $\mathrm{T}$ cells profile. Cells from HbSS subjects who had urinary tract infections (HbSS inf*, $n=12$ ), HbSS subjects who did not have a urinary tract infection (HbSS, $n=10)$, uninfected HbAS subjects $(n=10)$, and uninfected HbAA volunteers $(n=11)$ were activated with phorbol 12-myristate 13-acetate and stained

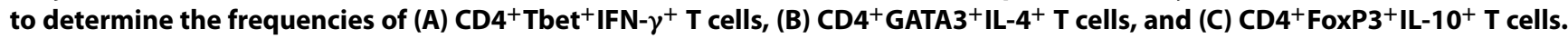
Bars indicate the percentages of cells, expressed as mean \pm SEM. Asterisks show statistical differences (Mann-Whitney $U$ test) between the groups ( $\left.{ }^{*} P<0.05\right)$.

strains isolated from infected HbSS subjects induced elevated IL-10 production compared to the unstimulated control (Figure 6C).

\section{DISCUSSION}

We investigated the systemic cytokine and $\mathrm{T}$ helper cell profiles of asymptomatic UTI in HbSS subjects in Togo. We observed that infected HbSS subjects had a significantly higher level of IFN- $\gamma$ than uninfected $\mathrm{HbSS}$ subjects. We also found that HbSS subjects, both infected and uninfected, had significantly higher plasma levels of IL-10 than $\mathrm{HbAA}$ and HbAS subjects (Figure 2). In addition, we could not detect IL-5, IL-6, or TNF- $\alpha$ in the plasma of any study group. Inves- tigating if Th cells were the main source of cytokines, we realized that the cytoplasmic and plasmatic cytokine levels did not follow the same trend.

$E$ coli antigens from infected HbSS subjects co-cultured with PBMCs of healthy donors induced significant production of TNF- $\alpha$ and IL-6 (Figure 5). Furthermore, all E coli antigens responsible for asymptomatic UTI induced significant production of IL-10 (Figure 6).

The pathophysiology of SCD is driven by polymerization of $\mathrm{HbS}$, leading to hemolysis and vaso-occlusive events; inflammation is a fundamental and constant component in these processes and can lead to tissue damage. ${ }^{24}$ Among bacterial infections in humans, UTI is prevalent, ${ }^{25}$ and 

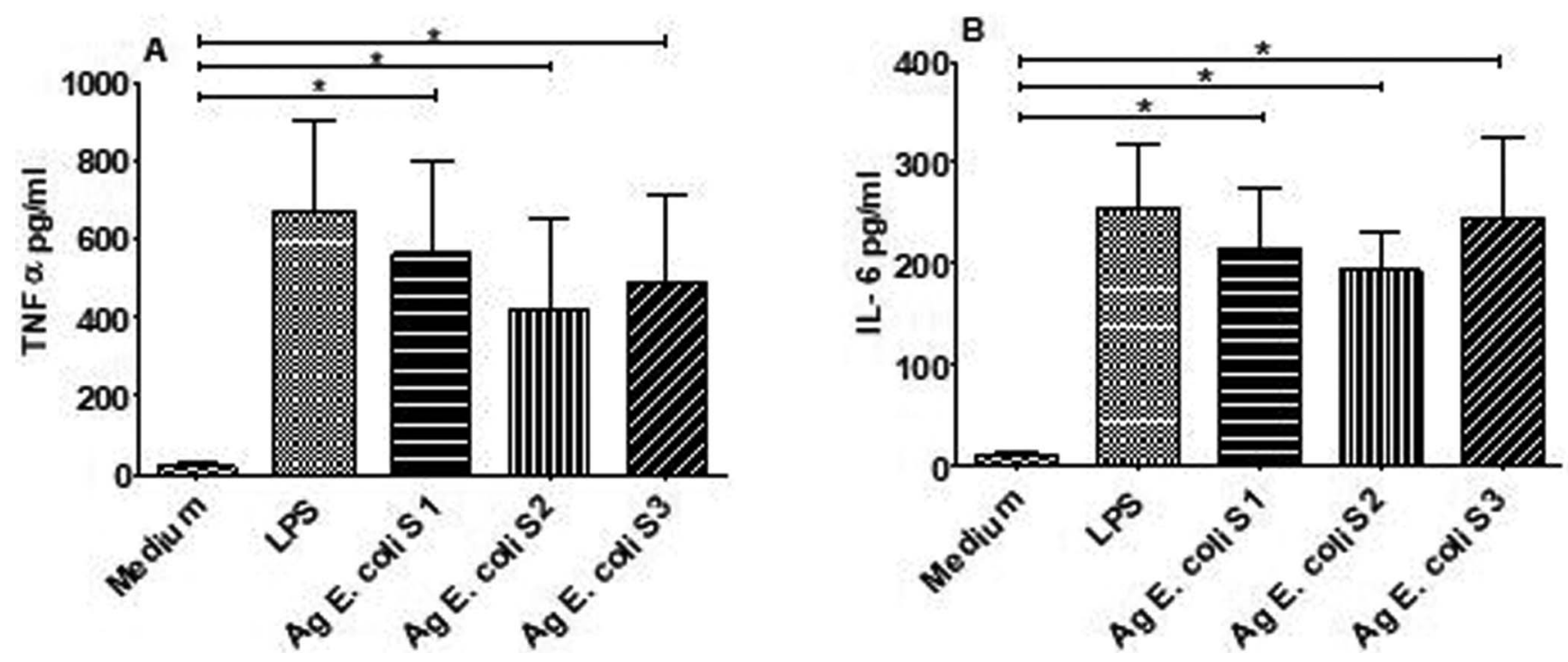

Figure 5. Immunogenicity of bacterial strains isolated from the urine of infected HbSS subjects after 24 hours of culture. Peripheral blood mononuclear cells (PBMCs) from healthy volunteer donors $(n=6)$ were stimulated with antigens (Ag) derived from bacterial strains (randomly named S1, S2, and S3). Bars indicate levels of type 1 cytokines: (A) tumor necrosis factor (TNF)- $\alpha$ and (B) interleukin (IL)-6. Medium indicates the well containing unstimulated cells. LPS indicates the well containing cells co-cultured with lipopolysaccharide. Asterisks show statistical differences (Mann-Whitney $U$ test) between the different co-cultures or PBMC stimulations performed $(* P<0.05)$.

patients with SCD have an increased susceptibility to bacterial infection. ${ }^{26}$ UTIs are more prevalent in females than males, ${ }^{27}$ and females were the majority of our infected HbSS study population, with a male to female ratio of $1: 11$. The implication of Th cells in UTI remain unclear. ${ }^{28}$

Infected HbSS subjects had a significantly higher rate of IFN- $\gamma$ than uninfected HbSS subjects. IFN- $\gamma$ is recognized as a key player in cellular immunity; it can orchestrate many protective functions to enhance immune responses in infections. ${ }^{29}$ Jones-Carson et al demonstrated that IFN- $\gamma$ is protective against UTIs; they found that IFN- $\gamma-$ knockout C57BL/6 mice compared to wild type mice were more likely to develop a UTI ${ }^{30}$; however, an acute/chronic inflammatory state can be damaging to tissues and organs. ${ }^{31}$

The cytokine profile data observed for females only (Figure 3) were approximately the same as the data observed in the 2 sexes (Figure 2), except we found no significant difference between the profiles of HbSS females and $\mathrm{HbAA}$ females. The lack of difference could be explained by the sample sizes: $3 \mathrm{HbAA}$ females vs 11 infected $\mathrm{HbSS}$ females and 6 uninfected $\mathrm{HbSS}$ females.

The plasma level of IL-10 in infected and uninfected HbSS subjects was higher than that in uninfected $\mathrm{HbAA}$ and $\mathrm{HbAS}$ subjects, and the difference was significant (Figure 2). As an immunomodulatory cytokine, IL-10 plays a central role in limiting the host immune response to pathogens, preventing host damage and maintaining normal tissue homeostasis. ${ }^{32}$ IL-10 is elevated during the steady state of SCD compared to normal controls. ${ }^{8,23}$ Because patients with SCD in this study were in steady state, the level of IL-10 is justified.

In patients with UTIs, IL-10 may protect the host against exaggerated immune responses that produce inflammation and tissue damage. ${ }^{16,33}$ An argument can therefore be made that high IL-10 levels are protective and may explain the absence of common UTI symptoms such as fever, pelvic pain, and micturition pain in infected patients.

TNF- $\alpha$, IL- 6 , and IL-5 were undetectable in the plasma of all study groups. TNF- $\alpha$ and IL- 6 are more implicated than other cytokines in severe UTIs. ${ }^{17}$ Siransy et al revealed high levels of IL- 6 in patients with SCD in crisis. ${ }^{34}$ IFN- $\gamma$, elevated as in this study, has been found to inhibit IL-5 production. ${ }^{35}$ Because our study groups consisted of asymptomatic UTI-infected HbSS subjects in steady state and uninfected $\mathrm{HbSS}, \mathrm{HbAS}$, and $\mathrm{HbAA}$ subjects, the levels of TNF- $\alpha$, IL-5, and IL- 6 may well be undetectable.

Several immune cells could release cytokines measured in plasma. $^{36}$ We found that the primary sources of IFN$\gamma$ and $\mathrm{IL}-10$ in the plasma of infected HbSS subjects were neither Th1 nor nTreg cells. Because the Th lymphocytes are not the source of the cytokines, we think that IFN- $\gamma$ and IL-10 are produced by macrophages. The 3 types of macrophages are naïve macrophages, classically activated macrophages that secrete IFN- $\gamma$, and alternatively activated macrophages that secrete IL-10. ${ }^{37}$ In cases of bacterial aggression, the bacteria stimulate the pathogen recognition receptors of immune cells-macrophages in this case-through pathogen-associated molecular patterns or damage-associated molecular patterns, and an immune response follows. For example, lipopolysaccharides, a major component of the $E$ coli outer membrane, binds to the toll-like receptor 4 (TLR4) of the macrophage, resulting in the production of IFN- $\gamma$ by the macrophage through a signaling pathway to interferon regulatory factor (IRF)-

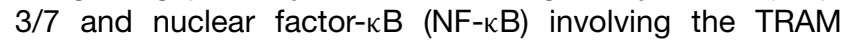
and TRIF adaptors. ${ }^{38}$ In addition, $E$ coli lipopolysaccharides linked to the macrophage TLR4 promote IL-10 production by the macrophage through a mitogen-activated protein kinase (MAPK) signaling pathway (extracellular 

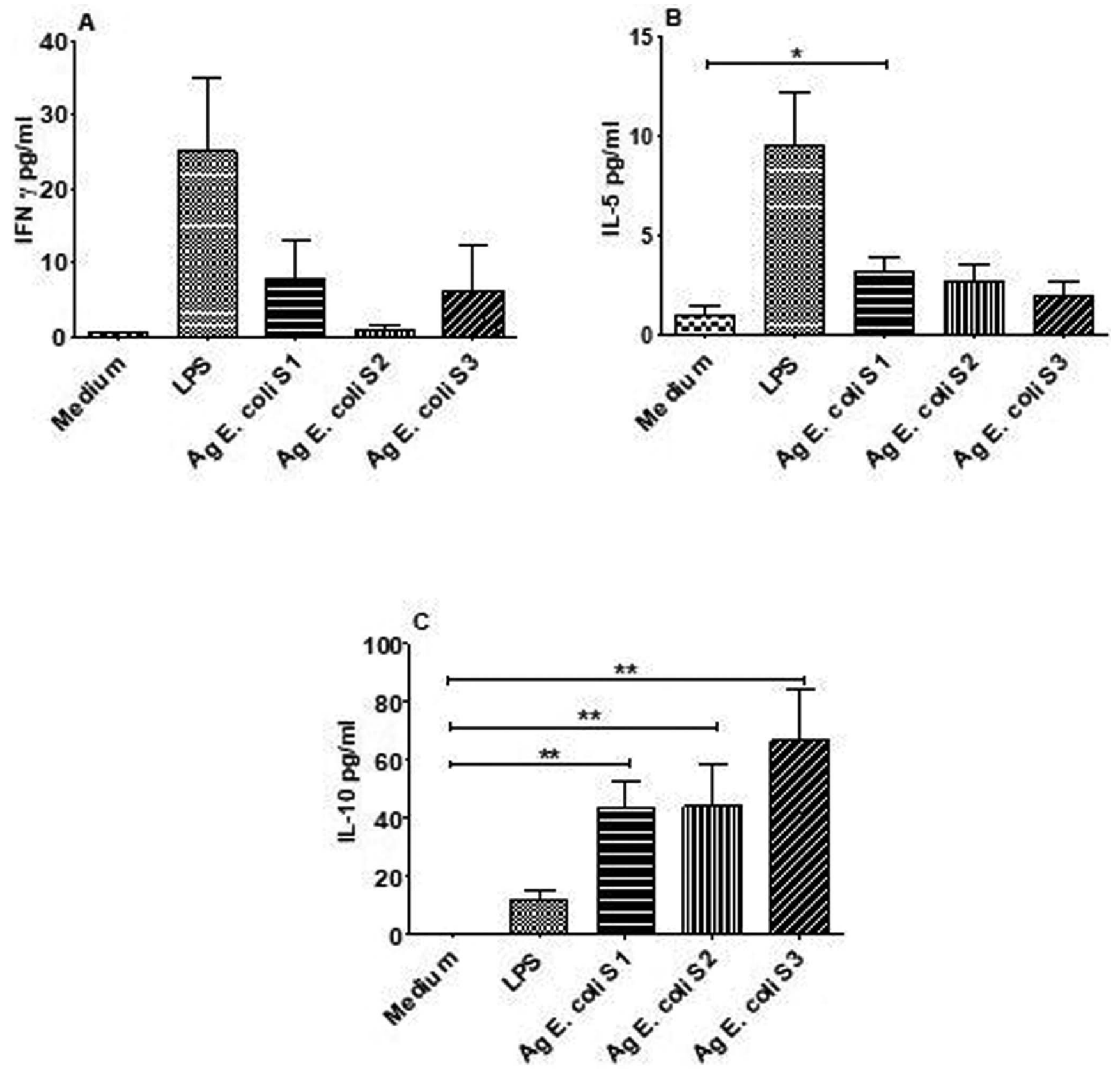

Figure 6. Immunogenicity of bacterial strains isolated from the urine of infected HbSS subjects after 72 hours of culture. Peripheral blood mononuclear cells (PBMCs) from healthy volunteer donors $(n=6)$ were stimulated with antigen (Ag) from bacterial strains (S1, S2, and S3). Bars indicate levels of type 2 cytokines: (A) interferon gamma (IFN- $\gamma$ ), (B) interleukin (IL)-5, and (C) IL-10. Medium indicates the well containing unstimulated cells. LPS indicates the well containing cells co-cultured with lipopolysaccharide. Asterisks show statistical differences (Mann-Whitney $U$ test) between the different co-cultures or PBMC stimulations performed $(* P<0.05)$.

signal-regulated kinase [ERK], MAPK p38) and transcription factors such as CREB, NF-кB, and homodimeric p50. ${ }^{39}$ Consequently, we can suppose that the source of IL-10 could be macrophages.

In addition, we found that both infected and uninfected HbSS subjects had significantly higher IL-10 plasma levels than uninfected $\mathrm{HbAS}$ and $\mathrm{HbAA}$ subjects. Macrophages have been found to be the major source of IL-10 in most inflammatory diseases, ${ }^{37}$ and they are among the major protagonists in the pathophysiology of SCD. ${ }^{40}$ Thus, increased
IL-10 could be associated with a normal steady-state condition in patients with SCD.

After stimulation of PBMCs from healthy donors, bacterial antigens induced activation and proliferation of immune cells. Thus, an immune response was triggered, and the immunogenicity of the $E$ coli strains was well verified.

The measurement of TNF- $\alpha$ and IL- 6 after 24 hours of stimulation allows for the exploration of innate immune response. In the innate response, the synergistic gene expression of cytokines TNF- $\alpha, \mathrm{IL}-6$, and even IL-10 and IL-12p70 is due 
to the combined stimulation of the TLR ligands through the $\mathrm{NF}-\kappa \mathrm{B}$, IFN regulatory factor, MAPK, phosphatidylinositol 3-kinases, and signal transducer and activator of transcription signaling pathways. ${ }^{41}$ In addition, gram-negative bacteria have been shown to induce high levels of TNF- $\alpha$ and IL-6 after 4 hours of stimulation of immune cells. ${ }^{42}$

Measuring IL-10 after 72 hours of stimulation allows for the exploration of the adaptive response. The $E$ coli extracts used in this study induced significant production of IL-10. Whole $E$ coli are effective inducers of IL-10 from human leukocytes. ${ }^{43}$ In addition, $E$ coli strains responsible for asymptomatic bacteriuria can downregulate the immune response in host cells. ${ }^{44}$

The CD4 ${ }^{+} \mathrm{T}$ lymphocyte profile observed after 72 hours of stimulation showed that $\mathrm{CD} 4^{+} \mathrm{T}$ lymphocytes were not the source of IL-10 in this study. In the adaptive immune response, IL-10 is produced not only by CD4 ${ }^{+} \mathrm{T}$ lymphocytes but also by $\mathrm{B}$ lymphocytes and CD8 ${ }^{+} \mathrm{T}_{\text {lymphocytes. }}{ }^{45}$ For example, lipopolysaccharides induce an optimal production of IL-10 by B lymphocytes after prolonged stimulation through the signaling pathway requiring myeloid differentiation factor 88.46

After co-culturing bacterial strains with cells from healthy volunteer donors, $E$ coli strains induced a high level of IL-10. The increased IL-10 production in HbSS subjects with asymptomatic UTI could be linked to different antigen expression by bacteria strains. Fully virulent uropathogenic $E$ coli strains have been shown to cause symptomatic UTI with acute inflammation and a strong innate immune response and tissue damage. ${ }^{47}$

This study has limitations in that we were not able to investigate a large number of subjects, and because of the skepticism of patients with SCD, we were unable to recollect blood from them to stimulate their PBMCs with $E$ coli antigens. Nevertheless, this study showed that HbSS subjects with asymptomatic UTI had elevated plasma levels of IFN- $\gamma$ and elevated IL-10 levels.

Together, these findings may explain that IL-10 concentration may be responsible for the asymptomatic status of UTI in the patients studied.

\section{CONCLUSION}

Our study demonstrated that HbSS subjects with UTIs had increased plasma levels of IFN- $\gamma$ associated with high levels of IL-10, but T helper cells were not the main source of those cytokines. These findings could indicate that the IL-10 environment may be responsible for asymptomatic UTIs in patients with SCD. Further studies should investigate the source of plasma IL-10. Systematic cytobacteriologic examination of the urine of HbSS subjects would be of interest.

\section{ACKNOWLEDGMENTS}

The authors have no financial or proprietary interest in the subject matter of this article.

\section{REFERENCES}

1. Williams NT. Sickle cell disease in Sub-Saharan Africa. Hematol Oncol Clin North Am. 2016;30(2):343-358. doi: 10.1016/j.hoc.2015.11.005

2. Piel FB, Steinberg MH, Rees DC. Sickle cell disease. N Engl J Med. 2017;376(16):1561-1573. doi: 10.1056/NEJMra1510865
3. Segbena AY, Kueviakoe IMD, Messie AK. Situation de la drepanocytose au Togo. J Rech Sci Univ. 2005;7(1).

4. Bandeira ICJ, Rocha LBS, Barbosa MC, et al. Chronic inflammatory state in sickle cell anemia patients is associated with $\mathrm{HBB}\left({ }^{*}\right) S$ haplotype. Cytokine. 2014;65(2):217-221. doi: 10.1016/j.cyto.2013.10.009

5. Pitanga NT, Vilas-Boas W, Cerqueira BAV, et al. Cytokine profiles in sickle cell anemia: pathways to be unraveled. Adv Biosci Biotechnol. 2013;4:6-12. doi: 10.4236/abb.2013.47A1002

6. Makis AC, Hatzimichael EC, Bourantas KL. The role of cytokines in sickle cell disease. Ann Hematol. 2000;79(8):407-413. doi: 10.1007/s002770000173

7. Keikhaei B, Mohseni AR, Norouzirad R, et al. Altered levels of pro-inflammatory cytokines in sickle cell disease patients during vaso-occlusive crises and the steady state condition. Eur Cytokine Netw. 2013;24(1):45-52. doi: 10.1684/ecn.2013.0328

8. Lanaro C, Franco-Penteado CF, Albuqueque DM, Saad STO, Conran N, Costa FF. Altered levels of cytokines and inflammatory mediators in plasma and leukocytes of sickle cell anemia patients and effects of hydroxyurea therapy. J Leukoc Biol. 2009;85(2):235-242. doi: 10.1189/jlb.0708445

9. Booth C, Inusa B, Obaro SK. Infection in sickle cell disease: a review. Int J Infect Dis. 2010;14(1):e2-e12.

10. Chemegni BC, Bamzok EKO, Sack FN, Ngouadjeu E, Mbanya D. Morbidité et mortalité chez les patients drépanocytaires au Service d'Hématologie de l'Hôpital Central de Yaoundé. Health Sci Dis. 2018.

11. Platt OS, Brambilla DJ, Rosse WF, et al. Mortality in sickle cell disease. Life expectancy and risk factors for early death. N Engl J Med. 1994;330(23):1639-1644. doi: 10.1056/NEJM199406093302303

12. Donkor ES, Osei JA, Anim-Baidoo I, Darkwah S. Risk of asymptomatic bacteriuria among people with sickle cell disease in Accra, Ghana. Diseases. 2017;5(1):4. doi: 10.3390/diseases5010004

13. Nath AK, Hebbel RP. Sickle cell disease: renal manifestations and mechanisms. Nat Rev Nephrol. 2015;11(3):161-171. doi: 10.1038/nrneph.2015.8

14. Nicolle LE, Bradley S, Colgan R, Rice JC, Schaeffer A, Hooton TM; Infectious Diseases Society of America; American Society of Nephrology; American Geriatric Society. Infectious Diseases Society of America guidelines for the diagnosis and treatment of asymptomatic bacteriuria in adults. Clin Infect Dis. 2005;40(5):643-654. doi: 10.1086/427507. Erratum in Nicolle et al. (2005; 40:643-54). Clin Infect Dis. 2005;40(10):1556. doi: $10.1086 / 430760$

15. Ochocinski D, Dalal M, Black LV, et al. Life-threatening infectious complications in sickle cell disease: a concise narrative review. Front Pediatr. 2020;8:38. doi: 10.3389/fped.2020.00038

16. Reygaert WC. Innate Immune Response to Urinary Tract Infections Involving Escherichia coli. J Clin Cell Immunol. 2014;5:280.

17. Gürgöze MK, Akarsu S, Yilmaz E, et al. Proinflammatory cytokines and procalcitonin in children with acute pyelonephritis. Pediatr Nephrol. 2005;20(10):1445-1448. doi: 10.1007/s00467-005-1941-6

18. Nguepou Tchopba C, Katawa G, Dossim S, Salou M, Vovor A, Ameyapoh YA. Asymptomatic urinary tract infections in homozygous sickle cell patients in Togo. Eur J Pharm Med Res. 2020;6(7):44-50.

19. Dason S, Dason JT, Kapoor A. Guidelines for the diagnosis and management of recurrent urinary tract infection in women. Can Urol Assoc J. 2011;5(5):316-322. 
20. Manuzak J, Dillon S, Wilson C. Differential interleukin-10 (IL-10) and IL-23 production by human blood monocytes and dendritic cells in response to commensal enteric bacteria. Clin Vaccine Immunol. 2012;19(8):1207-1217. doi: 10.1128/CVI.00282-12

21. Katawa G, Layland LE, Debrah AY, et al. Hyperreactive onchocerciasis is characterized by a combination of Th17-Th2 immune responses and reduced regulatory T cells. PLoS Negl Trop Dis. 2015;9(1):e3414. doi: 10.1371/journal.pntd.0003414

22. Oshiro Y, Morris DL. TNF-alpha release from human peripheral blood mononuclear cells to predict the proinflammatory activity of cytokines and growth factors. J Pharmacol Toxicol Methods. 1997;37(1):55-59. doi: 10.1016/s1056-8719(97)83624-6

23. Musa BOP, Onyemelukwe GC, Hambolu JO, Mamman Al, Isa $\mathrm{AH}$. Pattern of serum cytokine expression and T-cell subsets in sickle cell disease patients in vaso-occlusive crisis. Clin Vaccine Immunol. 2010;17(4):602-608. doi: 10.1128/CVI.00145-09

24. Torres LS, Okumura JV, Silva DGH, et al. Inflammation in sickle cell disease: differential and down-expressed plasma levels of annexin A1 protein. PLoS One. 2016;11(11):e0165833. doi: 10.1371/journal.pone. 0165833

25. McLellan LK, Hunstad DA. Urinary tract infection: pathogenesis and outlook. Trends Mol Med. 2016;22(11):946-957. doi: 10.1016/j.molmed.2016.09.003

26. Brousse $V$, Buffet $P$, Rees $D$. The spleen and sickle cell disease: the sick(led) spleen. Br J Haematol. 2014;166(2):165-176. doi: $10.1111 /$ bjh. 12950

27. Abraham SN, Miao Y. The nature of immune responses to urinary tract infections. Nat Rev Immunol. 2015;15(10):655-663. doi: $10.1038 /$ nri3887

28. Nielubowicz GR, Mobley HLT. Host-pathogen interactions in urinary tract infection. Nat Rev Urol. 2010;7(8):430-441. doi: 10.1038/nrurol.2010.101

29. Kak G, Raza M, Tiwari BK. Interferon-gamma (IFN- $\gamma$ ): exploring its implications in infectious diseases. Biomol Concepts. 2018;9(1):64-79. doi: 10.1515/bmc-2018-0007

30. Jones-Carson J, Balish E, Uehling DT. Susceptibility of immunodeficient gene-knockout mice to urinary tract infection. J Urol. 1999;161(1):338-341.

31. Chen L, Deng $\mathrm{H}$, Cui $\mathrm{H}$, et al. Inflammatory responses and inflammation-associated diseases in organs. Oncotarget. 2017;9(6):7204-7218. doi: 10.18632/oncotarget.23208

32. Murphy K, Weaver C, Supérieur DB, ed. Masson PL, trans. Immunobiologie de Janeway. 4th ed. 2018.

33. Mege JL, Meghari S, Honstettre A, Capo C, Raoult D. The two faces of interleukin 10 in human infectious diseases. Lancet Infect Dis. 2006;6(9):557-569. doi: 10.1016/S1473-3099(06)70577-1

34. Siransy LK, Yapo-Crézoit CCA, Diane KM, et al. Th1 and Th2 cytokines pattern among sickle cell disease patients in Côte d'Ivoire. J Clin Immunol Res. 2018. doi: 10.33425/2639-8494.1011

35. Wensky A, Marcondes MC, Lafaille JJ. The role of IFN-gamma in the production of Th2 subpopulations: implications for variable Th2-mediated pathologies in autoimmunity. J Immunol. 2001;167(6):3074-3081. doi: 10.4049/jimmunol.167.6.3074

36. Aziz N. Measurement of circulating cytokines and immune-activation markers by multiplex technology in the clinical setting: what are we really measuring? For Immunopathol Dis Therap. 2015;6(1-2):19-22. doi: 10.1615/ForumlmmunDisTher.2015014162

37. Kumar V. Macrophages: the potent immunoregulatory innate immune cells. In: Bhat KH, ed. Macrophage Activation: Biology and Disease. IntechOpen; 2020:1-30.

38. Fitzgerald KA, Rowe DC, Barnes BJ, et al. LPS-TLR4 signaling to IRF-3/7 and NF-kappaB involves the toll adapters TRAM and TRIF. J Exp Med. 2003;198(7):1043-1055. doi: $10.1084 /$ jem. 20031023

39. Sanin DE, Prendergast CT, Mountford AP. IL-10 production in macrophages is regulated by a TLR-driven CREB-mediated mechanism that is linked to genes involved in cell metabolism. J Immunol. 2015;195(3):1218-1232. doi: $10.4049 /$ jimmunol.1500146

40. Allali S, Maciel TT, Hermine O, de Montalembert M. Innate immune cells, major protagonists of sickle cell disease pathophysiology. Haematologica. 2020;105(2):273-283. doi: 10.3324/haematol.2019.229989

41. Mäkelä SM, Strengell M, Pietilä TE, Österlund P, Julkunen I. Multiple signaling pathways contribute to synergistic TLR ligand-dependent cytokine gene expression in human monocyte-derived macrophages and dendritic cells. J Leukoc Biol. 2009;85(4):664-672. doi: 10.1189/jlb.0808503

42. Kragsbjerg $P$, Söderquist B, Holmberg $H$, Vikerfors $T$, Danielsson D. Production of tumor necrosis factor-alpha and interleukin- 6 in whole blood stimulated by live Gram-negative and Gram-positive bacteria. Clin Microbiol Infect. 1998;4(3):129-134.

43. Hessle C, Hanson LA, Wold AE. Interleukin-10 produced by the innate immune system masks in vitro evidence of acquired T-cell immunity to E. coli. Scand J Immunol. 2000;52(1):13-20. doi: 10.1046/j.1365-3083.2000.00741.x

44. Lutay N, Ambite I, Hernandez JG, et al. Bacterial control of host gene expression through RNA polymerase II. J Clin Invest. 2013;123(6):2366-2379. doi: 10.1172/JCl66451

45. Kamanaka M, Kim ST, Wan YY, et al. Expression of interleukin-10 in intestinal lymphocytes detected by an interleukin-10 reporter knockin tiger mouse. Immunity. 2006;25(6):941-952. doi: 10.1016/j.immuni.2006.09.013

46. Kalampokis I, Yoshizaki A, Tedder TF. IL-10-producing regulatory B cells (B10 cells) in autoimmune disease. Arthritis Res Ther. 2013;15 Suppl 1(Suppl 1):S1. doi: 10.1186/ar3907

47. Salvador E, Wagenlehner F, Köhler CD, et al. Comparison of asymptomatic bacteriuria Escherichia coli isolates from healthy individuals versus those from hospital patients shows that long-term bladder colonization selects for attenuated virulence phenotypes. Infect Immun. 2012;80(2):668-678. doi: 10.1128/IAI.06191-11

This article meets the Accreditation Council for Graduate Medical Education and the American Board of Medical Specialties Maintenance of Certification competencies for Patient Care and Medical Knowledge.

(C2021 by the author(s); licensee Ochsner Journal, Ochsner Clinic Foundation, New Orleans, LA. This article is an open (i) access article distributed under the terms and conditions of the Creative Commons Attribution (CC BY) license (creativecommons.org/licenses/by/4.0/legalcode) that permits unrestricted use, distribution, and reproduction in any medium, provided the original author(s) and source are credited. 